\title{
中国城市群空间结构的演化与影响因素 基于人口分布的形态单中心一多中心视角
}

\author{
孙斌栋 1,2 , 华杰媛 1,3 , 李 琬 ${ }^{1,2}$, 张婷麟 1,2 \\ (1. 华东师范大学中国现代城市研究中心, 上海 200062; 2. 华东师范大学城市与区域科学学院, 上海 200241; \\ 3. 福建省同安第一中学, 福建 厦门 361199)
}

\begin{abstract}
摘 要: 城市群是未来中国城镇化的主要空间载体, 研究城市群空间结构的演化特征和影响因素具有重要意义。已 有文献较少从形态单中心一多中心视角研究中国城市群空间结构的演化和影响因素, 而且通常采用户籍人口而非 常住人口测度城市群空间结构, 导致测量误差。为解决这个问题, 本文采用基于人口普查的常住人口数据进行分 析, 并运用联合国数据对结果进行佐证。以已有文献采用客观标准界定的 13 个城市群为样本, 使用规模-位序法 则测度城市群的形态单中心一多中心程度,探究城市群的空间结构演化趋势和影响因素。结果发现, 1980年代以 来大多数城市群的空间结构呈现多中心化趋势; 人均 GDP 水平的提高和人口规模的增加是导致城市群空间结构 多中心化的主要原因。因此,政府对于空间结构偏多中心的城市群,应强化城市间的交通联系和政策一体化,获取 更大的发展红利;对于个别处于单中心化阶段的城市群,政策导向则避免过早地多中心化。
\end{abstract}

关 键 词: 城市群;空间结构; 演化; 影响因素;单中心; 多中心; 中国

\section{1 引言}

城市群(City Cluster)是指由若干都市区构成、 空间相邻和功能紧密相关的巨型城市化区域。随 着城市之间社会经济联系日益密切, 城市群已经成 为世界性的地理现象。进入快速城市化阶段的中 国将城市群作为支撑未来发展的主要空间载体和 国家参与全球竞争与国际分工的地域单元。

在西方学术界, 与城市群含义接近的概念包括 Megalopolis, Megapolitan Area, Mega- region 和 mega-city Region。法国地理学家 Gottmann(1957) 最早提出 “城市群” (Megalopolis) 概念, 并将美国东 北部大西洋沿岸出现的由多个大城市组成的巨型 城市化区域定义为城市群。Lang 等(2007)研究发 现美国已形成 10 个城市群(Megapolitan area), 且每
个城市群由两个或两个以上的大都市区(Metropoli$\tan$ area)组成。Florida等(2008)基于灯光数据界定 出全球 40 个城市群(Mega-region), 发现其经济总量 占全球产出的 66\%。Hall等(2006)则针对西北欧提 出了巨型城市区域(Mega-city Region)的概念。在 欧美国家,还有很多相似的城市区域概念, 如“Urban Field” "Polynucleated Urban Field” "Polycentric Urban Region(PUR)" "Polycentricity" "City- region” (Kloosterman et al, 2001; Davoudi, 2003)。不过, 这 些概念所界定的空间尺度小于前面所提的城市群。

近年来, 对于欧洲城市群的单中心一多中心结 构研究相对较多, 且包括形态、功能等多个维度。 国外有关城市群空间结构内容主要包括: (1)在城市 群空间结构及演化方面, Bailey等(2001)发现, 尽管 苏格兰中部的多中心城市区域在形态上呈现多中

收稿日期: 2017-03; 修订日期: 2017-09。

基金项目: 国家自然科学基金项目(41471139); 教育部人文社会科学重点研究基地基金项目(16JJD790012); 上海哲学社会科 学规划课题(2014BCK003)[Foundation: National Natural Science Foundation of China, No.41471139; The MOE Project of Key Research Institute of Humanities and Social Sciences at Universities, No.16JJD790012; Project of Philosophy \& Social Science of Shanghai, No.2014BCK003]。

作者简介: 孙斌栋(1970-), 男, 河北阜平人, 博士, 教授, 博导, 主要研究方向为城市地理和经济地理, E-mail: bdsun@re.ecnu.edu.cn。 
心特点, 但在功能上表现出单中心特征。而 Hall等 (2006)对西北欧 8 个巨型城市区域(Mega-city Region)的形态和功能多中心性研究发现, 尽管只有兰 斯塔德和莱茵鲁尔是典型的形态多中心分布, 但功 能上多数都呈现多中心化的特征。Lambooy(1998) 发现兰斯塔德的人口和经济处于不断地分散中, 但 更高的经济水平和文化功能需要更大的集聚。 Riguelle等(2007)发现, 比利时城市群的就业尽管多 中心分散化发展, 但整体的形态多中心程度仍然较 低。(2)在空间结构影响因素方面, Halbert(2008)发 现信息密集型产业阻碍了巴黎区域的多中心的持 续发展。Hall等(2006)也发现全球化和信息基础设 施使得西北欧巨型城市区域更加集聚, 因而对城市 群发展的多中心战略能否有效提高效率提出怀 疑。(3)在城市群空间结构经济绩效方面, Bailey等 (2001)发现, 苏格兰中部作为多中心城市区域进行 的规划并未发挥应有的效益,多中心城市区域的集 聚效应不如同等规模的单中心城市。Meijers(2005) 发现, 兰斯塔德作为多中心的一个成功案例, 协同 作用虽然在加强但是经济上的互补性却在减弱。 Oort等(2010)的实证研究也发现, 兰斯塔德还未形 成一体化经济。

在中国城市群的研究中,姚士谋首次使用“城 市群”命名中国大尺度的城市密集地域, 不过, 关于 中国城市群的定义和识别存在不同的标准和看法 (周一星等, 1988; 姚士谋, 1992; 苗长虹等, 2005; 方 创琳, 2009; 宁越敏, 2011)。已有文献还研究了城 市群空间结构的特征、演化、成长阶段以及演化机 制, 涉及多个城市 (薛东前等, 2003; 邓丽君等, 2010; 曾鹏等, 2011), 或者仅关注某个单一城市群 (叶玉瑶, 2006; 汤放华等, 2010), 主要是采用描述或 定性分析方法。

近几年虽已开始出现关于中国城市群的定量 研究, 但存在明显不足。首先, 数量很少, 结论也不 完全一致。(1)在城市群的空间结构及其演化方面, Liu等(2016)发现东部沿海的城市群在形态与功能 上达到高度的多中心性, 而西部的城市群则多半缺 乏多中心性; 赵璟等(2009)以中国西部地区7个城 市群为例, 认为城市群空间结构逐渐由前期的单中 心化向近年的多中心化转变; 但也有研究显示, 国 内城市群空间结构整体上呈单中心化趋势(张浩然 等, 2012; 李佳洺等, 2014)。(2)在城市群空间结构 演化的影响因素方面, 赵璟等(2009)发现, 人均 GDP、人口规模、政府支出规模和贸易成本的增加
会阻碍城市群空间结构由首位分布向多中心演变; 但赵志成(2014)对中部城市群的研究却发现, 政府 支出的扩大会促进城市群空间结构的多中心化。 (3)极少量文献涉及城市群空间结构的经济绩效, 其 结论也不一致(张浩然等, 2012; 李佳洺等, 2014)。 其次, 由于对城市群识别标准存在争议, 这些实证 研究所采用的城市群样本并不相同, 如李佳洺等 (2014)的样本包括 20 多个城市群(引自方创琳, 2009), 而张浩然等(2012)则使用了 10 大城市群(引 自曾鹏等, 2011)。最后,城市群空间结构的测度大 多数基于户籍人口, 且在测度空间结构时, 除赵璟 等(2009)考虑了县级单元外,其他研究都是仅仅基 于地级市,因而准确性不高。

区域空间结构演变理论为研究城市群空间结 构演化提供了重要基础。弗里德曼相对完整地阐 述了区域空间结构随着经济发展阶段的推进, 从低 水平空间均衡到单中心增长极再到高水平多中心 均衡的演化过程(Friedmann, 1966)。陆大道在总结 文献基础上提出的四阶段区域空间结构演变理论, 阐述了空间结构演变的动力基础(陆大道, 1988)。 如果说地理学家和城市规划学者侧重于描述空间 结构与经济发展的互动关系, 而经济学家则力图解 释其中的机制。Marshall(1890)发现了产业地方化 集聚的现象,并提出了集聚的 3 个好处。以 Krugman(1991b)和 Fujita等(1999)等为代表的新经济地 理学运用主流经济学的范式和理论模型模拟方法, 解释了马歇尔所关注的产业集聚的原因,认为空间 集聚有助于获得规模报酬递增。这些理论为城市 群先期发展阶段的集聚提供了具有说服力的解 释。然而, 集聚不是无限制的。随着城市人口或经 济的扩张,交通拥堵、环境污染等集聚的负外部性 带来的成本将会超过正外部性。理论模拟显示, 集 聚不经济的产生可能推动空间结构从单中心向多 中心转变(Fujita et al, 1982; Krugman, 1991b, 1996)。

总之, 中外学术界对于城市群的研究从形态、 功能、联系等多个视角展开。形态角度的城市群研 究, 主要从人口的集聚一分散或人口分布的单中心 一多中心视角进行, 主要运用人口或就业数据分 析。越来越多文献开始进行功能和联系视角下的 城市群研究, 主要采用公司内部网络和交通数据来 测度城市群内空间关系。但从本文所关注的形态 视角来看, 关于城市群现象、概念界定以及特征描 述相对较多, 而关于城市群演化规律和影响因素虽 有不少探讨, 但以定性和简单定量分析居多, 研究 
对象往往集中在一个或少数几个城市群, 采用规范 的多元计量分析方法展开的大样本研究较少, 结论 也不完全一致。

基于以上研究现状, 本文力图从以下几方面创 新: 首先, 从形态单中心一多中心视角研究中国城 市群空间结构的演化趋势和影响因素, 为城市群的 理论发展提供来自中国的经验和证据。其次, 在定 量分析方法上, 采用规范的多元回归分析模型, 检 验在其他因素既定情况下, 每个影响因素对于城市 群空间结构变化的影响, 相较于简单数据说明和两 个变量间的相关分析, 结果更加可信, 并可对已有 文献不尽一致的研究结论作进一步检验。最后, 所 采用的城市群识别标准和方法较以往更加客观可 靠: 不是根据主观规划和政策意向来选择城市群样 本, 而是根据客观数据标准界定城市群; 所用数据 基于人口普查的常住人口, 较以往探索城市群空间 结构与影响因素文献(赵璟等, 2009; 张浩然等, 2012; 李佳洺等, 2014)所通常使用的户籍人口可更 准确地测度城市群的空间结构, 并运用联合国数据 进行结果的佐证和稳健性分析; 以往分析所使用地 理单元更多为地级市, 而本文则细化到县级单元, 能更全面地刻画城市群空间结构。

\section{2 研究对象与数据来源}

\section{1 研究对象}

由于对城市群的识别标准不同, 不同学者界定 出的城市群在数量和空间范围上都存在较大差 异。宁越敏(2011)基于中国常住人口数据, 综合城 市化水平和人口密度等指标界定出大都市区, 再以 大都市区为基本组成单元界定出中国的城市群。 相比于其他界定方法, 其界定标准更为客观统一, 界定出的城市群也更加接近城市集聚区域实体。 因此, 本文选用宁越敏界定的 13 个规模较大的城市 群为研究对象, 其空间分布如图 1, 具体包括长三 角、珠三角、京津唐、辽中南、山东半岛、闽东南、成 渝、中原、关中、哈大齐、长吉、武汉和长株潭共 13 个 城市群。每个城市群内部所包含的地级及以上城 市如表 1 所示, 括号内数字表示每个城市群分别在 1990 年、 2000 年、 2010 年所包含的地理单元(市辖区
整体、县和县级市)的数量。从表 1 可以发现,在 1990-2010 年间, 大多数城市群所辖地域单元数有 减少的趋势。

\section{2 数据来源}

改革开放以来, 随着中国社会经济的迅速发

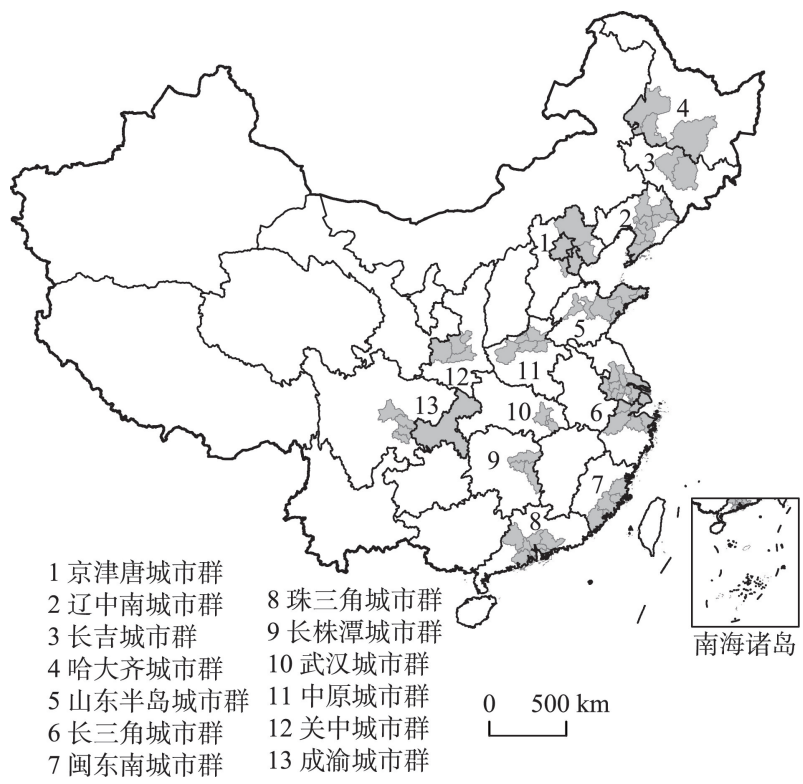

图 1 中国城市群分布情况

Fig.1 Distribution of city clusters in China

表 1 中国城市群范围

Tab.1 The scope of China's city clusters

\begin{tabular}{ll}
\hline 城市群 & \multicolumn{1}{c}{ 地级及以上城市 } \\
\hline 长三角 & 上海、苏州、无锡、常州、镇江、南京、扬州、泰州、南通、杭 \\
& 广嘉兴、湖州、绍兴、宁波、舟山(88-82-68) \\
珠三角 & 广州、深圳、佛山、江门、惠州、珠海、东莞、中山、肇庆 \\
& (38-31-24) \\
京津唐 & 北京、天津、廊坊、唐山、秦皇岛(40-36-30) \\
辽中南 & 沈阳、鞍山、抚顺、本溪、辽阳、营口、大连(24-29-29) \\
山东半岛 济南、青岛、淄博、潍坊、烟台、威海(40-38-37) \\
闽东南 & 福州、莆田、泉州、厦门、漳州(32-31-30) \\
成渝 & 成都、资阳、内江、自贡、重庆(32-30-27) \\
中原 & 郑州、开封、洛阳、新乡、焦作、济源(40-42-42) \\
关中 & 西安、咸阳、铜川、宝鸡(34-33-30) \\
哈大齐 & 哈尔滨、大庆、齐齐哈尔(17-29-27) \\
长吉 & 长春、吉林(12-11-11) \\
武汉 & 武汉、鄂州、黄石(8-5-5) \\
长株潭 & 长沙、株洲、湘潭(14-15-15) \\
\hline
\end{tabular}

资料来源:引自宁越敏(2011)

(1)根据第六次人口普查数据, 综合六大指标, 城市群范围有所调整, 但变化不大。只有武汉城市群地域发生变化, 在原范围的 基础上,加人了孝感、黄冈、咸宁、仙桃、潜江、天门六个城市(宁越敏, 2016)。考虑到本文研究样本偏少,而武汉城市群范围突 然变大可能影响模型估计偏误,故武汉城市群仍以基于四普人口确定的范围为准。 
展, 城市化进程不断加快, 使得跨区域的人口流动 非常频繁, 户籍人口中的非农人口数据已不能真实 地反映中国城市经济活动人口的空间布局, 而只有 普查年份的常住人口才能更为真实地反映城市化 发展过程和城市地域的空间演变。即便是普查年 份的人口数据, 由于受建国以来市、建制镇标准的 频繁变化, 以及统计口径参差不齐的影响, 导致城 市群空间结构的准确测度具有一定难度。

为弥补数据缺陷, 对本文重点关注的城市群空 间结构, 采用两套数据测度城市群空间结构, 便于 进行结论稳健性的互为检验。第一套数据是中国 每隔 10 年一次的人口普查数据, 考虑到人口统计指 标从 1990 年的第四次人口普查开始相对统一, 且本 文所需的城市群其他社会经济数据主要来源《中国 城市统计年鉴》从 1984 年才开始,故采用 1990 年、 2000 年和 2010 年 3 个年份的人口普查分区县数据 测度城市群空间结构, 避免以往文献采用非普查年 份户籍人口作为依据的弊端。但由于这套数据只 有 3 个截面, 样本量偏少是其不足。第二套数据是 联合国人口司经济和社会事务部公布的 2014 年城 镇人口大于 30 万的城市(Urban Agglomerations)样 本以及这些城市自 1950 年以来至 2014 年的城镇人 口数据, 是基于城市实体地域的人口统计, 其范围 大致和中国地级市的市辖区或县级市市区一致。 其他社会经济数据来源于《中国城市统计年鉴》, 由 相应年份的城市数据进行加总。对应第一套城市 群空间结构数据, 构建了 13 个城市群 1990、2000 和 2010 年 3 个截面的面板数据。受制于 1984 年的城 市统计数据, 对应第二套城市群空间结构数据的分 析从 1984 年开始。由于城市群空间结构演化相对 较慢, 故每隔 2 年取偶数年为样本, 从而构建了 13 个城市群 1984-2012 年跨 15 个截面的长面板数 据。这套数据的优点为可进行较长时间周期的分 析, 样本量较大。其不足之处是, 2014 年较大的城 市(超过 30 万)在滞后年份里不一定是足够大的城 市, 或许在滞后年份里存在更大的城市, 从而可能 造成一定估计误差。不过, 以三普、四普、五普的常 住人口数据进行对比可以发现, 1990 年以来城市群 内部人口规模较大的城市基本不变, 未出现因人口 猛增或迅速减少而导致城市位序发生变化的现象, 故其误差可以接受, 且可用普查数据结果作检验。

\section{3 城市群空间结构演化}

本文借鉴 Meijers 等(2010)研究美国大都市区
空间结构做法, 采用城市的位序规模分布特征反映 城市群空间结构的单中心一多中心程度。规模-位 序法如式(1)。

$$
N_{i}=\frac{N_{1}}{R_{i}^{q}}
$$

式中: $N_{i}$ 是第 $i$ 位城市的人口规模; $N_{1}$ 是规模最大 的城市人口; $R_{i}$ 是第 $i$ 位城市的位序; $q$ 是待估计的 常数, 当其为 1 时, 通常认为城市规模分布符合齐普 夫定律(Zipf's Law)。对式(1)进行对数变换, 可得到 式(2)。

$$
\ln N_{i}=\ln N_{1}-q \ln R_{i}
$$

式中: $i$ 表示组成城市群的地理单元; $R_{i}$ 表示 $i$ 地理单 元的城镇人口在城市群范围内的位次排序; $N_{i}$ 是 第 $i$ 位地理单元的城镇人口规模; $N_{1}$ 表示城市群内 人口规模最大的地理单元。用其回归斜率 $q$ 来构造 城市群空间结构指数 $P$, 当 $P$ 值大于 1 时, 表示城市 规模分布倾向于集中分布或者说单中心分布; 反 之, 当其小于 1 时, 倾向于多中心分布。由于地级及 以上城市的市辖区、县级市及县都是功能相对独立 的城市实体, 故将其作为测度城市群空间结构的基 本地理单元, 并根据常住城镇人口数的位次进行 排序。

由图 2 可知,在 1990-2010期间,除了个别城市 群外,城市群空间结构总体呈现明显的多中心化趋 势。表 1 显示,各个城市群所包含的基本地理单元 个数总体上是减少的, 主要是由于核心城市市辖区 不断吞并外围的县或县级市所致,该因素会导致城 市群单中心化; 而真正的多中心化则应排除城市群 由于行政区划调整和地理单元个数增加而导致的 空间结构变化。1990年 13 个城市群空间结构指数 均大于 1 , 单中心程度较高, 其中, 关中、京津唐、武 汉城市群的单中心程度更为突出。到 2010 年, 除武

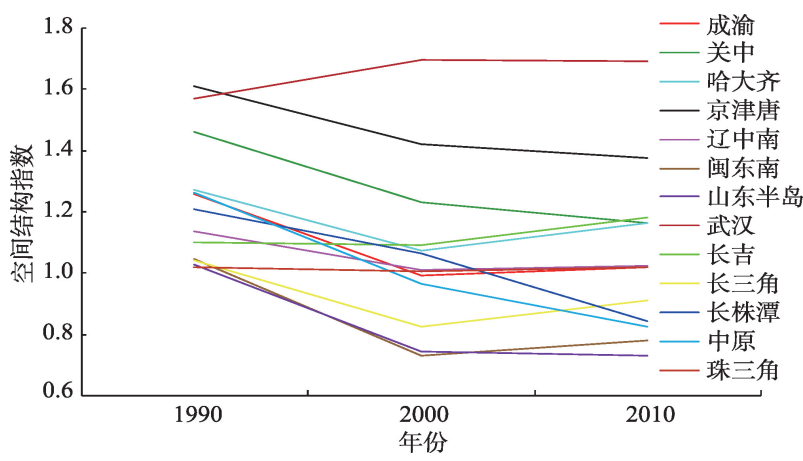

图 2 中国城市群空间结构演化趋势(基于人口普查数据)

Fig.2 Change in spatial structure of city clusters in China (based on census data) 
汉、京津唐、关中、长吉、哈大齐 5 个城市群空间结构 指数仍然大于 1 外, 其余城市群空间结构指数都小 于或等于 1 。与总体趋势不同的是, 武汉城市群在 1990-2010年期间, 长吉、长三角、哈大齐、闽东南城 市群在 2000-2010 年期间出现了单中心化趋势, 主 要的原因可能有 2 个: 一是行政区划调整。武汉城 市群在此期间撤销汉阳县、武昌县成立武汉市蔡甸 区、江夏区; 长三角城市群位居前列的大城市也存 在较频繁的“撤县设区”, 如南汇县、奉贤县并人上 海市辖区, 江宁县、江浦县、六合县并人南京市辖 区, 萧山市和余杭市并人杭州市辖区等。撤县设区 使得这些大城市市辖区人口规模 “人为”增大, 这是 城市群在相应时段内单中心化的重要原因。二是 由于城市群人口的集聚过程, 如哈大齐、长吉和闽 东南城市群,在 2000-2010期间行政区划基本不变, 空间结构指数明显上升, 说明这些城市群确实处于 单中心集聚的过程。

联合国数据可使我们从更长时间段来考察中 国城市群的空间演化规律。自 1950-2014年, 中国 13 个城市群的空间结构演化同样呈多中心化趋势, 即使在与上面普查数据相同时段的 1990-2010 期 间, 多中心化也是主要特征, 与图 2 反映的趋势是一 致的。

\section{4 城市群空间结构演化的影响因素}

\section{1 模型与变量}

本文采用面板数据模型检验城市群空间结构 演化的影响因素,计量回归模型公式为:

$$
y_{i t}=\alpha_{i}+Z_{i} \gamma+x_{i t} \beta+u_{i t}
$$

式中: $i$ 表示城市群; $t$ 表示年份; 被解释变量 $y_{i t}$ 代表 城市群空间结构; 采用前文定义的城市群空间结构 指数 $p ; \alpha_{i}$ 表示城市群不随时间变化的常数项, 用于 控制各城市群不被观察到的、不随时间变化的差异 性; $Z_{i}$ 也表示城市群不随时间变化的常数项, 但是可 以被观察到的城市群的个体差异性, 如地理位置、 地貌环境等自然禀赋; $\gamma$ 表示这些常数项的系数; $x_{i t}$ 表示随时间和城市群个体而变的解释变量, 如经济 发展水平、产业结构、政府干预等社会经济因素, 是 本文主要考虑的解释变量; $\beta$ 代表各解释变量的系 数; $u_{i t}$ 是随机扰动项, 满足零均值和同方差的假设。

根据以往的研究成果, 影响城市群空间结构演 化的因素可分为 2 类, 一类是自然禀赋因素, 包括地 貌环境、资源丰度、面积大小等; 另一类是社会经济
因素,包括城市群经济发展水平、人口规模、产业结 构、政府干预等。这些因素会影响城市群社会经济 活动在空间上的集聚和分散，从而导致空间结构的 演变。这些影响因素构成本文回归分析中的解释 变量,具体模型如公式(4)。

$$
\begin{aligned}
P_{i}= & \alpha \ln p g d p_{i}+\beta \ln \text { area }_{i}+\gamma \ln \text { pop }_{i}+\delta \text { secter }_{i}+ \\
& {\text { g } \text { gov }_{i}+\text { plninfra }_{i}+\mu \text { fcap }_{i}+\varepsilon_{i}}
\end{aligned}
$$

式中: $\alpha 、 \beta 、 \gamma 、 \delta 、 \theta 、 \varphi$ 和 $\mu$ 为待估计的变量系 数, $\varepsilon$ 为残差。其他变量含义和构造方法如下:

(1) $P_{i}$ 为空间结构指数。表示由式(2)测算出的 城市群 $i$ 的空间结构指数。

(2) $p g d p_{i}$ 为经济发展水平。经济发展水平的高 低可通过影响区内各种微观社会经济行为并改变 其空间分布方式,从而进一步改变城市群的空间结 构。按照弗里德曼的集聚扩散理论, 发展初期阶 段, 区域更倾向于集聚或单中心,而后期阶段将走 向分散和多中心。城市群的经济发展主要来自非 农经济, 故用城市群第二产业和第三产业生产总值 之和除以城镇总人口得到人均 GDP 来衡量城市群 的经济发展水平。为消除物价水平差异带来的影 响, 选择 1990 年为基年(联合国人口司数据以 1984 年为基期),利用历年《中国统计年鉴》中省(市)层面 的地区生产总值调整指数对每个城市的地方生产 总值进行平减。

(3) $\mathrm{area}_{i}$ 为行政区面积。土地面积作为表征自 然资源丰度和生产活动的空间载体, 可通过土地和 交通运输成本来影响经济活动的集聚和扩散, 从而 影响城市群空间结构。本文采用城市群的行政区 面积, 考察地域大小对城市群空间结构单中心一多 中心程度的影响。

(4) $\mathrm{pop}_{i}$ 为人口规模。采用城市群常住城镇人 口, 考察城市群规模集聚效应对其空间结构的影 响。随着人口增加, 城市由初期的集聚发展逐渐因 集聚不经济而趋向分散。

(5) secter $_{i}$ 为产业结构。以第二产业生产总值 与第三产业生产总值的比例为代理变量。通常认 为, 制造业占比代表的集聚经济能促进人口集中。 但 Fujita等(1999)认为,标准化生产的成熟制造业从 大城市中获得的集聚效益较小, 却要支付高地租和 高工资, 于是倾向于朝成本较低的低等级城市扩 散。本文采用第二、三产比率来考察产业结构对城 市群空间结构演化的影响。

(6) gov $_{i}$ 为政府干预。用上一级政府财政支出 占城市群 GDP 的比重表示。政府在区域发展过程 
中担任重要角色, 若其在政策制定过程中有城市偏 好, 则会影响各经济要素在城市之间的配置, 从而 影响城市群的空间结构。

(7) $i n f r a_{i}$ 为交通基础设施。交通设施水平高低 能影响交通运输成本, 从而影响产业等经济活动的 集聚和扩散。由于城市群内城市间道路交通设施 数据可得性的限制, 本文采用城市群内所有城市的 道路面积总和除以常住城镇总人口得到的人均道 路面积作为代理变量, 考察交通设施水平对城市群 空间结构演化的影响

(8) $f_{c a p}$ 为开放度。外商投资如果对经济发展 水平较好的城市群核心城市有偏好, 那么将有利于 促进城市群单中心化发展。本文采用当年实际利 用外资金额占 GDP 比重, 考察全球化经济对城市群 空间结构的影响。

以上解释变量除产业结构、政府干预和开放度 为比例或比重数据外,其余都采取对数形式。表 2 给出了基于人口普查数据上述各变量在 1990 、 $2000 、 2010$ 年的均值和标准差。由此可以发现, 13 个城市群的空间结构指数在 1990-2010年之间不断 降低, 即再次印证了多中心化趋势。城市群经济发 展水平、城镇人口规模以及交通设施水平 (人均道 路面积)均呈上升趋势, 行政区面积基本保持稳定, 第二、三产业的比重则呈降低趋势, 这与直观感受
一致; 上级政府财政支出占 GDP 比重有先降低后升 高的趋势, 而实际利用外资金额占 GDP 比重有先升 高后降低的过程。

\section{2 回归结果}

首先是基于 1990 、2000 和 2010 年三次人口普 查数据的结果。通常在社会经济研究中,由于不可 观测的异质性会对解释变量有影响,因而一般使用 固定效应模型, 随机效应比较少见, 特别在观测单 位比较大的地理区域, 固定效应更为合适(伍德里 奇, 2010; 陈强, 2014)。为减轻可能的遗漏变量所 带来的内生性问题, 同时也考虑到本文样本偏少, 不适合于随机效应模型(表3), 因而回归结果(1)-(5)

\section{表 2 各变量描述性统计}

Tab.2 Descriptive statistics of variables

\begin{tabular}{|c|c|c|c|c|c|c|}
\hline \multirow{2}{*}{ 变量 } & \multicolumn{2}{|c|}{ 1990年 } & \multicolumn{2}{|c|}{2000 年 } & \multicolumn{2}{|c|}{ 2010年 } \\
\hline & 均值 & & 均值 & 标准差 & 均值 & 标准差 \\
\hline 空间结构指 & 1.226 & 0.204 & 1.065 & 0.266 & 1.056 & 0.266 \\
\hline 经济发展水平 $(\ln )$ & 8.374 & 0.3 & 8.8 & 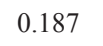 & 7 & .248 \\
\hline 人口规模(ln) & 6.758 & 0.608 & 7.141 & 0.659 & 7.480 & 0.717 \\
\hline 行政区面积(ln) & 10.837 & 0.608 & 10.865 & 0.571 & 10.870 & 0.569 \\
\hline 产业结构 & 1.878 & 0.455 & 1.1 & 0.277 & 1.238 & 0.24 \\
\hline 政府干预 & 20.736 & 12.430 & 13.835 & 7.923 & 24.320 & 11.496 \\
\hline 交通基础设 & -0.460 & 0.972 & 0.342 & 0.969 & 2.277 & 0.718 \\
\hline 开放度 & 2.470 & 2.499 & 4.282 & 3.519 & 3.408 & 1.744 \\
\hline
\end{tabular}

表 3 城市群空间结构演化的影响因素(1990-2010)

Tab.3 Influencing factors of spatial structure change of city clusters in China, 1990-2010

\begin{tabular}{|c|c|c|c|c|c|c|}
\hline 变量 & (1) FE & (2) $\mathrm{FE}$ & (3) $\mathrm{FE}$ & (4) $\mathrm{FE}$ & (5) $\mathrm{FE}$ & (6) RE \\
\hline \multirow[t]{2}{*}{ 经济发展水平(1n) } & $-0.2670^{* * *}$ & -0.1704 & $-0.2411^{* *}$ & $-0.3163^{* * *}$ & $-0.2789^{* * *}$ & $-0.2844^{* * *}$ \\
\hline & $(0.087)$ & $(0.097)$ & $(0.088)$ & $(0.074)$ & $(0.086)$ & $(0.066)$ \\
\hline \multirow[t]{2}{*}{ 人口规模 $(\ln )$} & & $-0.1398^{* *}$ & $-0.1559^{*}$ & $-0.3439^{* *}$ & $-0.3452^{* *}$ & 0.0058 \\
\hline & & $(0.060)$ & $(0.074)$ & $(0.133)$ & $(0.131)$ & $(0.114)$ \\
\hline \multirow[t]{2}{*}{ 行政区面积(ln) } & & 0.0019 & 0.0285 & 0.0121 & -0.0030 & 0.0325 \\
\hline & & $(0.061)$ & $(0.062)$ & $(0.083)$ & $(0.082)$ & $(0.055)$ \\
\hline \multirow[t]{2}{*}{ 产业结构 } & & & -0.0725 & -0.0845 & -0.0827 & -0.0466 \\
\hline & & & $(0.063)$ & $(0.070)$ & $(0.066)$ & $(0.045)$ \\
\hline \multirow[t]{2}{*}{ 政府干预 } & & & 0.0006 & -0.0036 & -0.0031 & 0.0013 \\
\hline & & & $(0.002)$ & $(0.004)$ & $(0.004)$ & $(0.003)$ \\
\hline \multirow[t]{2}{*}{ 交通基础设施(ln) } & & & & $0.0680^{*}$ & $0.0652^{*}$ & -0.0466 \\
\hline & & & & $(0.037)$ & $(0.036)$ & $(0.048)$ \\
\hline \multirow[t]{2}{*}{ 开放度 } & & & & & -0.0080 & -0.0024 \\
\hline & & & & & $(0.008)$ & $(0.007)$ \\
\hline \multirow[t]{2}{*}{ 常数项 } & $3.4362^{* * *}$ & $3.5714^{* * * *}$ & $4.1051^{* * *}$ & $6.3271^{* * *}$ & $6.1916^{* * *}$ & $3.2604^{* * *}$ \\
\hline & $(0.754)$ & $(0.714)$ & $(0.581)$ & $(1.412)$ & $(1.334)$ & $(1.048)$ \\
\hline 调整 $R^{2}$ & 0.438 & 0.557 & 0.579 & 0.640 & 0.650 & 0.6033 \\
\hline 样本量 & 39 & 39 & 39 & 39 & 39 & 39 \\
\hline 截面个数 & 13 & 13 & 13 & 13 & 13 & 13 \\
\hline
\end{tabular}

注: ****”分别表示可以在 $1 \% 、 5 \%$ 和 $10 \%$ 的水平下通过显著性检验; 括号内数值为稳健标准误。 
以固定效应模型( $\mathrm{FE}$ )为基准, 同时也给出随机效应 模型 $(R E)$ 结果(6)作为对照。首先在表 3 模型 1 中单 独放人经济发展水平变量, 其系数在 $1 \%$ 的水平上 显著为负; 接着逐步加人其他控制变量, 经济发展 水平的系数依然高度显著为负, 说明随着经济发展 水平的提高,城市群空间结构会向多中心化发展。 人口规模系数在各模型中都显著为负, 说明城市群 城镇人口规模的扩大会促进城市群空间结构的多 中心化发展。交通基础设施水平显著为正, 说明交 通设施质量的提高降低了集聚不经济或运输成本, 从而更有利于各要素在核心城市的集聚,支持了 Krugman(1991a)的观点。(6)给出了随机效应模型 的结果, 可以看出, 经济发展水平结果依旧显著为 负, 不过人口规模和交通变量不再显著。后文选择 固定效应模型结果作为讨论基准。

由于基于人口普查的面板数据样本量偏少, 可 能会存在误差, 故将根据联合国公布数据构建的 1984-2012 年跨 15 期的长面板数据进行补充验证。 由于时间维度较大, 对可能存在的固定效应, 加人 个体虚拟变量; 对于时间效应, 加上时间趋势项控 制。对模型进行相关检验后发现, 样本存在组间异 方差、组内自相关或组间同期相关, 又因时间维度 并不比城市群个体数大很多, 可能无法提供足够多 的信息来分别估计每个城市群个体的 $\rho_{i}$, 故约束每 个城市群个体的自回归系数 $\rho$ 均相等, 因此使用全 面FGLS 进行估计更为合适(陈强, 2014)。

回归结果如表 4 中的模型(1)所示。经济发展 水平和人口规模的系数显著为负, 与表 3 回归结果 一致。考虑到经济发展水平对城市群空间结构的 影响可能存在一定的滞后效应, 即城市群经济发展 水平对人口等要素在空间上的重组变化需要一定 的作用时间, 还考虑到经济发展水平和空间结构之 间可能存在互为因果的内生性问题, 故以经济发展 水平的滞后值作为核心变量, 进一步考察城市群经 济发展水平对空间结构的影响。如模型(2)和(3)所 示, 滞后一期和二期(即滞后 2 年和 4 年)的经济发展 水平对空间结构的影响均显著为负, 说明经济发展 水平的提高将促进城市群空间结构向多中心化发 展, 这一结论较为稳健。人口规模同样显著为负, 与表 3 结果一致。

与表 3 结果不同的是,城市群行政区面积影响 开始变得显著, 而且符号为正, 一种可能的解释为: 行政区面积大的城市群纳人了更多的边缘地区的 中小城市, 从而使得空间分布更加单中心化。产业
表 4 城市群空间结构演化的影响因素(1984-2012)

Tab.4 Influencing factors of spatial structure change of city clusters in China, 1984-2012

\begin{tabular}{|c|c|c|c|}
\hline 变量 & (1) FGLS & (2) FGLS & (3) FGLS \\
\hline \multirow[t]{2}{*}{ 经济发展水平 $(\ln )$} & $-0.0106^{* * *}$ & & \\
\hline & $(0.000)$ & & \\
\hline \multirow[t]{2}{*}{ 经济发展水平滞后一期( $(\mathrm{ln})$} & & $-0.0134^{* * *}$ & \\
\hline & & $(0.000)$ & \\
\hline \multirow[t]{2}{*}{ 经济发展水平滞后二期( $(\mathrm{ln})$} & & & $-0.0172^{* * *}$ \\
\hline & & & $(0.001)$ \\
\hline \multirow[t]{2}{*}{ 人口规模 $(\ln )$} & $-0.2495^{* * *}$ & $-0.2679^{* * *}$ & $-0.2803^{* * *}$ \\
\hline & $(0.002)$ & $(0.001)$ & $(0.001)$ \\
\hline \multirow[t]{2}{*}{ 行政区面积(ln) } & $0.0324^{* * * *}$ & $0.0575^{* * *}$ & $0.0552^{* * * *}$ \\
\hline & $(0.001)$ & $(0.001)$ & $(0.001)$ \\
\hline \multirow[t]{2}{*}{ 产业结构 } & $0.0113^{* * * *}$ & $0.0319^{* * *}$ & $0.0083^{* * *}$ \\
\hline & $(0.000)$ & $(0.001)$ & $(0.003)$ \\
\hline \multirow[t]{2}{*}{ 政府干预 } & $-0.0909^{* * * *}$ & $-0.0550^{* * *}$ & $-0.0963^{* * *}$ \\
\hline & $(0.004)$ & $(0.001)$ & $(0.002)$ \\
\hline \multirow[t]{2}{*}{ 交通基础设施(1n) } & $0.0028^{* * * *}$ & $-0.0023^{* * *}$ & $-0.0101^{* * *}$ \\
\hline & $(0.000)$ & $(0.000)$ & $(0.000)$ \\
\hline \multirow[t]{2}{*}{ 开放度 } & $-0.0230^{* * *}$ & $0.1308^{* * *}$ & $-0.1024^{* * *}$ \\
\hline & $(0.004)$ & $(0.004)$ & $(0.010)$ \\
\hline 时间效应 & 控制 & 控制 & 控制 \\
\hline 个体效应 & 控制 & 控制 & 控制 \\
\hline \multirow[t]{2}{*}{ 常数项 } & $2.7075^{* * *}$ & $2.6197^{* * * *}$ & $2.6951^{* *}$ \\
\hline & $(0.017)$ & $(0.029)$ & $(0.032)$ \\
\hline 样本量 & 195 & 182 & 169 \\
\hline 截面个数 & 13 & 13 & 13 \\
\hline
\end{tabular}

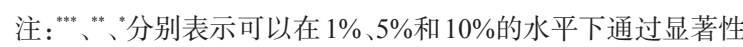
检验; 括号内数值为稳健标准误。

结构和政府干预在模型中分别显著为正和负, 说明 二产比重提高有助于促进城市群集聚发展,而后者 则促进了城市群均衡发展。交通基础设施在各模 型结果中符号并不稳定, 在基准模型即(1)为正, 与 表 3 结果一致; 但在经济发展水平滞后的模型(2)和 (3)中, 交通改善作用则更多地体现在促进多中心演 化。开放则促进了城市群多中心结构趋势。

\section{3 结果讨论}

由于数据限制, 本文基于 3 年人口普查和联合 国人口司数据构建的 2 套面板数据模型, 对城市群 空间结构影响因素的检验结果虽略有差异,但经济 发展水平和人口规模对城市群空间结构的影响非 常稳健, 即城市群经济发展水平的提高、人口规模 的扩大均会促使城市群空间结构朝多中心化趋势 发展。这一结论和赵璟等(2009)的研究结论相反, 可能的原因是其研究对象为西部地区的 7 个城市 
群,这些城市群可能还不是真正意义上的“城市 群”, 或者还处于城市群的初期阶段, 仍以集聚为 主。而本文样本为全国范围内的 13 个城市群, 发展 较为成熟,多数开始进人多中心扩散发展阶段。

从其他因素的结果来看, 第二产业比重高有助 于促进城市群单中心集聚, 说明中国城市主体上还 处于工业化集聚阶段,这一点符合中国发展实际, 也与赵璟等(2009)关于中国西部城市群的结论相 同; 同时, 这一结论与 Fujita等(1999)认为制造业已 经呈现分散态势的观点不同, 可能后者更多是发达 国家处于后工业化阶段的现实。

加强政府干预在本文中显示出促进多中心形 成的效应,表明中国当前政府偏好和政策总体上是 促进城市群的均衡发展。这一结论也与赵璟等 (2009)关于政府支出规模增加会阻碍城市群空间结 构由首位分布向多中心演变的结论相左, 表明研究 样本的差异会导致结论不同, 后者更多地反映了中 国西部不发达地区政府偏爱中心城市的倾向,因而 这一差异是可以理解的。

对外开放则促进了城市群内部各地区的发展， 推动了多中心演化, 与中国对外开放政策从核心城 市扩展到周边区域有关, 同时也表明外资企业的空 间选址动态变化。交通基础设施的改善对于城市 群空间结构的影响不够稳健, 由于相关交通数据的 不完善, 需要在今后获取可靠数据后作进一步检验。

\section{5 结论与启示}

本文以中国 13 个城市群为研究对象, 综合运用 1990-2010年中国人口普查年份的数据以及联合国 人口司公布的 1984-2012 年的数据, 采用规模位序 法测度了中国城市群空间结构, 运用面板数据的估 计方法对城市群空间结构演化的影响因素进行实 证研究。研究发现, 中国城市群空间结构在 1980年 代以来呈现多中心化的趋势; 人均 GDP 水平的提高 和人口规模的增加是导致城市群空间结构多中心 化的主要原因。

上述结论表明, 中国目前主要城市群多数已经 处于多中心发展阶段, 不过也有个别城市群尚处于 单中心集聚阶段。处于哪种发展阶段与经济发展 水平有关, 因为处于单中心化过程中的城市群大都 位于经济欠发达的西部地区和经济转型的东北地 区。而城市群空间结构演化的影响因素表明,经济 发展水平和人口规模增加会促进多中心化演变。
本文结论对于中国城市群的发展具有重要启示。 基于多数城市群的多中心化趋势, 政府应该顺势而 为,在城市群的基础设施建设方面为多中心化作好 准备,强化城市群城市间的交通联系,为各种生产 要素的互连互通创造条件;还要在制度和政策上加 快城市群内部一体化发展, 获取多中心化的更大红 利; 对于个别尚处于单中心化阶段的城市群, 应以 获取集聚效应为主,避免因盲目多中心化导致的经 济效率损失。

对于空间结构与经济发展之间存在的内生关 系, 限于数据和方法, 本文所揭示的影响因素与城 市群空间结构之间仍是一种相关关系, 识别因果关 系还需进一步探索,这也是该研究领域亟待攻克的 难点。而且, 正如本文在文献评价中所指出的, 越 来越多的文献开始运用经济和交通数据从功能联 系角度展开城市群分析, 这也是本文研究未来应该 拓展的方向。

\section{参考文献 (References)}

陈强. 2014. 高级计量经济学及 Stata应用[M]. 2 版. 北京: 高 等教育出版社. [Chen Q. 2014. Gaoji jiliang jingjixue ji Stata yingyong[M]. 2nd ed. Beijing, China: Higher Education Press.]

邓丽君, 张平宇, 李平. 2010. 中国十大城市群人口与经济发 展平衡性分析 [J]. 中国科学院研究生院学报, 27(2): 154162. [Deng L J, Zhang P Y, Li P. 2010. Equilibrium of population and economic development in the top ten urban agglomerations in China[J]. Journal of the Graduate School of the Chinese Academy of Sciences, 27(2): 154-162.]

方创琳. 2009. 城市群空间范围识别标准的研究进展与基本 判断[J]. 城市规划学刊, (4): 1-6. [Fang C L. 2009. Research progress and general definition about identification standards of urban agglomeration space[J]. Urban Planning Forum, (4): 1-6.]

李佳洺, 张文忠, 孙铁山, 等. 2014. 中国城市群集聚特征与 经济绩效 [J]. 地理学报, 69(4): 474-484. [Li J M, Zhang W Z, Sun T S, et al. 2014. Characteristics of clustering and economic performance of urban agglomerations in China [J]. Acta Geographica Sinica, 69(4): 474-484.]

陆大道. 1988. 区位论及区域研究方法 [M]. 北京: 科学出版 社. [Lu D D. 1988. Quweilun ji quyu yanjiu fangfa[M]. Beijing, China: Science Press.]

苗长虹, 王海江. 2005. 中国城市群发展态势分析 [J]. 城市发 展研究, 12(4): 11-14. [Miao C H, Wang H J. 2005. The analysis on developmental situations of China's urban agglomerations[J]. Urban Studies, 12(4): 11-14.]

宁越敏. 2011. 中国都市区和大城市群的界定: 兼论大城市 群在区域经济发展中的作用[J]. 地理科学, 31(3): 257263. [Ning Y M. 2011. Definition of Chinese metropolitan 
areas and large urban agglomerations: Role of large urban agglomerations in regional development[J]. Scientia Geographica Sinica, 31(3): 257-263.]

宁越敏. 2016. 论中国城市群的发展和建设 [J]. 区域经济评 论, (1): 124-130. [Ning Y M. 2016. The development and construction of Chinese city cluster [J]. Regional Economic Review, (1): 124-130.]

汤放华, 陈立立, 曾志伟, 等. 2010. 城市群空间结构演化趋 势与空间重构: 以长株潭城市群为例 [J]. 城市发展研究, 17(3): 65-69, 85. [Tang F H, Chen L L, Zeng Z W, et al. 2010. Evolution tends and restructuring of spatial structure about urban agglomeration: By the case of Chang-Zhu-Tan agglomeration[J]. Urban Studies, 17(3): 65-69, 85.]

伍德里奇. 2010. 计量经济学导论 [M]. 费剑平, 译. 4 版. 北 京: 中国人民大学出版社. [Wooldridge J M. 2010. Introductory econometrics[M]. Fei J P, Trans.. 4th ed. Beijing, China: China Renmin University Press.]

薛东前, 孙建平. 2003. 城市群体结构及其演进 [J]. 人文地 理, 18(4): 64-68. [Xue D Q, Sun J P. 2003. Structure of urban agglomeration and its evolution[J]. Human Geography, 18(4): 64-68.]

姚士谋. 1992. 我国城市群的特征、类型与空间布局 [J]. 城市 问题, (1): 10-15. [Yao S M. 1992. Woguo chengshiqun de tezheng, leixing yu kongjian buju[J]. Urban Problems, 1992, (1): 10-15.]

叶玉瑶. 2006. 城市群空间演化动力机制初探: 以珠江三角 洲城市群为例 [J]. 城市规划, 30(1): 61-66, 87. [Ye Y Y. 2006. Spatial evolution mechanism of urban conglomeration: A case study of the Pearl River Delta[J]. City Planning Review, 30(1): 61-66, 87.]

曾鹏, 黄图毅, 阙菲菲. 2011. 中国十大城市群空间结构特征 比较研究 [J]. 经济地理, 31(4): 603-608. [Zeng P, Huang T Y, Que F F. 2011. Comparative study on spatial structure characteristics of Chinese ten top urban agglomeration[J]. Economic Geography, 31(4): 603-608.]

张浩然, 衣保中. 2012. 城市群空间结构特征与经济绩效: 来 自中国的经验证据 [J]. 经济评论, (1): 42-47. [Zhang H R, Yi B Z. 2012. Spatial structure and economic performance in Chinese urban agglomerations[J]. Economic Review, (1): 42-47.]

赵璟, 党兴华, 王修来. 2009. 城市群空间结构的演变: 来自 中国西部地区的经验证据 [J]. 经济评论, (4): 27-34. [Zhao J, Dang X H, Wang X L. 2009. Chengshiqun kongjian jiegou de yanbian: Laizi Zhongguo xibu diqu de jingyan zhengju[J]. Economic Review, (4): 27-34.]

赵志成. 2014. 产业集聚与城市群空间结构互动关系研究: 以中部城市群为例[D]. 太原: 太原科技大学. [Zhao Z C. 2004. The research on the relationship between industrial agglomeration and urban agglomeration spatial structure: A case study of urban agglomerations in central region[D]. Tai- yuan, China: Taiyuan University of Science and Technology.] 周一星, 于艇. 1988. 对我国城市发展方针的讨论 [J]. 城市规 划, (3): 33-36. [Zhou Y X, Yu T. 1988. Dui woguo chengshi fazhan fangzhen de taolun[J]. City Planning Review, (3): 33-36.]

Bailey N, Turok I. 2001. Central Scotland as a polycentric urban region: Useful planning concept or chimera[J]. Urban Studies, 38(4): 697-715.

Davoudi S. 2003. European Briefing: Polycentricity in European spatial planning: From an analytical tool to a normative agenda[J]. European Planning Studies, 11(8): 979-999.

Florida R, Gulden T, Mellander C. 2008. The rise of the megaregion[J]. Cambridge Journal of Regions, Economy and Society, 1(3): 459-476.

Friedmann J. 1966. Regional development policy: A case study of Venezuela[J]. Urban Studies, 4(3): 309-311.

Fujita M, Krugman P, Venables A J. 1999. The spatial economy: Cities, regions, and international trade[M]. Cambridge, MA: MIT Press.

Fujita M, Ogawa H. 1982. Multiple equilibria and structural transition of non-monocentric urban configurations[J]. Regional Science and Urban Economics, 12(2): 161-196.

Gottmann J. 1957. Megalopolis or the urbanization of the northeastern seaboard[J]. Economic Geography, 33(3): 189-200.

Halbert L. 2008. Examining the mega-city-region hypothesis: Evidence from the Paris City-region/Bassin parisien[J]. Regional Studies, 42(8): 1147-1160.

Hall P G, Pain K. 2006. The polycentric metropolis: Learning from Mega-City regions in Europe[M]. London, UK: Earthscan.

Kloosterman R C, Musterd S. 2001. The polycentric urban region: Towards a research agenda[J]. Urban Studies, 38(4): 623-633.

Krugman P R. 1991a. Geography and trade[J]. Southern Economic Journal, 1.

Krugman P R. 1991b. Increasing returns and economic geography[J]. Journal of Political Economy, 99(3): 483-499.

Krugman P R. 1996. The self-organizing economy[M]. Cambridge, Mass: Blackwell Publishers.

Lambooy J G. 1998. Polynucleation and economic development: The randstad[J]. European Planning Studies, 6(4): 457-466.

Lang R E, Nelson A C. 2007. Beyond metroplex: Examining commuter patterns at the "megapolitan" scale[R]. Cambridge, MA: Lincoln Institute of Land Policy.

Liu X J, Derudder B, Wu K. 2016. Measuring polycentric urban development in China: An intercity transportation network perspective[J]. Regional Studies, 50(8): 1302-1315.

Marshall A. 1890. Principles of economics: An introductory volume[M]. London, UK: Macmillan. 
Meijers E. 2005. Polycentric urban regions and the quest for synergy: Is a network of cities more than the sum of the parts[J]. Urban Studies, 42(4): 765-781.

Meijers E J, Burger M J. 2010. Spatial structure and productivity in US metropolitan areas[J]. Environment and Planning A, 42(6): 1383-1402.

Riguelle F, Thomas I, Verhetsel A. 2007. Measuring urban polycentrism: A European case study and its implications [J]. Journal of Economic Geography, 7(2): 193-215.

van Oort F, Burger M, Raspe O. 2010. On the economic foundation of the urban network paradigm: Spatial integration, functional integration and economic complementarities within the Dutch Randstad[J]. Urban Studies, 47(4): 725748 .

\title{
Spatial structure change and influencing factors of city clusters in China: From monocentric to polycentric based on population distribution
}

\author{
SUN Bindong ${ }^{1,2}$, HUA Jieyuan ${ }^{1,3}$, LI Wan ${ }^{1,2}$, ZHANG Tinglin ${ }^{1,2}$ \\ (1. Center for Modern Chinese City Studies, East China Normal University, Shanghai 200062, China; \\ 2. School of Urban and Regional Science, East China Normal University, Shanghai 200241, China; \\ 3. Tong'an No.1 Middle School of Fujian, Xiamen 361199, Fujian, China)
}

\begin{abstract}
With the significant increase of social and economic interactions among constituent cities, city clusters have become the most striking geographic phenomenon in the twenty-first century. In the latest regional development strategy, city clusters have been positioned as the main spatial carriers of socioeconomic activities by the Chinese government. Although an increasing number of scholars has described the characteristics and proposed definitions of city clusters, there have been surprisingly few studies on the morphological change and influencing factors of city clusters' spatial structure based on population data. In most existing empirical studies on city cluster, instead of permanent resident population, registered household (hukou) population was used to measure city clusters' spatial structure and this introduces error. Hence, in this study we used two different sources of data-permanent resident population from the Chinese Census, and population of urban agglomerations released by the United Nations population division. Our sample is comprised of 13 city clusters.. Rank-size rule was applied to measure the morphological characteristics. The principal objective of this study is to examine the change and influencing factors of the spatial structure of Chinese city clusters. Our descriptive statistics show that there was a clear tendency towards polycentricity of city clusters during 1990-2010. Using two panel data analysis techniques (FE and FGLS) and different databases, we found that all else being equal, the spatial polycentricity of the city clusters is mainly associated with the increases of GDP per capita and population size. Most city clusters are in the stage of polycentricity, and only a few remain in the earlier monocentric stage. These findings have important policy implications for the development of urban clusters. For most city clusters with a polycentric tendency, the governments should promote integration within city clusters through transportation and regional coordination policies that strengthen the exchange of production factors and improve economic performance. For the few city clusters of monocentricity, however, the governments should avoid introducing polycentricity oriented policies too soon, which could be harmful to their economic performance. Due to methodological and data limitations, the endogenous problem between spatial structure and economic development is difficult to solve. The spatial structure of city clusters can be regarded as both a cause and a consequence of economic development. Hence, this two-way relationship might be correlative rather than causal. Further work should push forward in this regard to identify the real cause- effect. In addition, an increasing literature uses economic and transportation data to analyze city clusters from the perspective of functional linkage. This represents another direction that future research should focus on.
\end{abstract}

Key words: city clusters; spatial structure; change; influencing factors; monocentricity; polycentricity; China 